\title{
Cell Division Process
}

National Cancer Institute

\section{Source}

National Cancer Institute. Cell Division Process. NCI Thesaurus. Code C21102.

A cellular mechanism directly involved in the process of cell division. 